reanalyse their data using probabilities that take into account the effect of single sex selection.

JOHN T. O'BRIEN

PSE

Fulbourn Hospital

Cambridge CBI SEF

SIR: Lacey et al (Journal, August 1991, 159, 291) have repeated their claim that female bulimics from twochild families would be expected, by chance, to have twice as many brothers as sisters. This erroneous claim led them to interpret their own data that brothers and sisters were roughly equally common as evidence that all-female sibships represent a risk factor for bulimia. They are right, of course, that malefemale sibships are roughly twice as common in the general population as female-female sibships. They have forgotten, however, that they were twice as likely to ascertain the latter since either sister could present at their clinic. Assume, for example, that bulimia led to clinic referral in 1 in 1000 females. Lacey et al would then have had a 1 in 1000 chance of including any sibship with just one female (such as a male-female sibship), but a 2 in 1000 chance of including any sibship with two females (assuming the risk was equal but independent for both sisters). After allowing for this unequal ascertainment, malefemale and female-female sibships should have been equally common in their sample. Since their results do not differ significantly from this expectation, their findings do not suggest that women from all-female sibships are at greater risk of bulimia.

Institute of Psychiatry

ROBERT GOODMAN

De Crespigny Park

Denmark Hill

London SE5 8 AF

\section{Apparent decrease in schizophrenia}

SIR: Eagles (Journal, June 1991, 158, 834-835) comments on the findings of Der et al (1990) as part of a growing body of evidence that suggests the incidence of schizophrenia is decreasing (e.g. Eagles et al, 1988). Methodological and diagnostic complexities notwithstanding, these observations are compelling, as they have been noted in both hospital (first-admission) and community-based populations.

Eagles cites possible explanations for this phenomenon, including changing environmental risk factors such as decreased perinatal injury and decreased prevalence and/or incidence of various infectious diseases. To this list we would like to add changing patterns of exposure to illicit and recreational drugs.
Bowers (1987) studied data from Connecticut state hospitals for the years 1967-1979 and concluded that an increase in first admissions of substance-abusing patients was followed in three to five years by an increase in first admission rates for schizophrenic and paranoid disorders. The association was particularly strong for young psychotic patients. Similarly, McLellan et al (1979) reported that five out of 11 military veterans with stimulant and hallucinogen abuse requiring repeated hospital admission developed psychotic disorders during a six-year followup. Psychoses were specific to stimulant abusers when compared to patients abusing depressants and opiates.

We agree with Eagles that study of the social and demographic features of the specific population which has shown the greatest decline of schizophrenia would be helpful in explaining this apparent decrease. Among those features worth investigating would be recreational drug use and its relationship to the incidence and course of psychotic illness in that population.

BOWERS, M. B., Jr (1987) The role of drugs in the production of schizophreniform psychoses and related disorders. In Psychopharmacology: The Third Generation of Progress (ed. H. Y. Meltzer). New York: Raven Press.

Der, G., Gupta, S. \& Murray, R. M. (1990) Is schizophrenia disappearing? Lancet, 335, 513-516.

Eagles, J. M., Hunter, D. \& MCCANCE, C. (1988) Decline in the diagnosis of schizophrenia among first contacts with psychiatric services in North-East Scotland, 1969-1984. British Journal of Psychiatry, 152, 793-798.

Mclellan, A. T., Woody, G. E. \& O'Brien, C. P. (1979) Development of psychiatric illness in drug abusers: possible role of drug preference. New England Journal of Medicine, 301, 1310-1314.

\section{SCOTT MCCORMICK} DONald C. GoFF

Erich Lindemann Mental Health Center

Massachusetts General Hospital

Boston, Massachusetts

USA

\section{The human brain and political behaviour}

SIR: Hugh Freeman's explanation of political behaviour in largely psychological - psychopathological terms made interesting reading (Journal, July $1991,159,19-32)$. However, to extend the argument, "a crooked molecule behind a crooked thought" to "a crooked molecule behind a crooked policy" appears too simplistic, hardly capable of explaining any complex sociocultural phenomenon.

The paper's major thrust is that social and political changes result from individual actions, which are in turn influenced by personality and psychopathology. Although individuals as leaders do seem to change 
the course of human societies, a particular social milieu throws up individuals who emerge as leaders at times conducive to change. The assumption that the influence of an individual on society is unidirectional is fallacious. A Germany fed on Nietzsche's philosophy and Wagner's music, unable to get over the World War I defeat, and reeling under intense unemployment and economic crises, could groom only a Hitler as its leader.

Cultural and economic factors that influence social processes do not always lend themselves to psychological explanations. Ryle makes the interesting distinction in his example: if a man returns from the market with his pigs unsold because the price was lower than he expected, the explanation is economic. However, if he returns with his pigs because he would not sell them at any price to a customer with a certain look in his eyes, the explanation might be psychological (Ryle, 1949).

I suspect that political decisions which have proved disastrous are explained away as resulting from individual psychological maladies. In the same issue of the Journal, Meyer Lindberg explains how German psychiatrists connived with the holocaust. To explain collective wrongdoing on the basis of individual pathology may be attractive as well as relieving, but it does not bring us any closer to the real explanations behind sociopolitical changes.

RyLE, G. (1949) The Concept of Mind. Middlesex: Penguin Books.

Department of Psychiatry

Swaran P. Singh

Queen's Medical Centre

Nottingham NG7 2UH

SIR: Your measured overview of the relationship between psychobiology and political institutions (Journal, July 1991, 159, 19-32) correctly warns us against the overinclusive theories evolved by the psychohistorians and our easy tendency to pathologise political movements and leaders of whom we disapprove. The self-serving nature of the accusations (both Bush and Saddam recently calling each other 'insane') has done much to restrict the debate to the margins of both psychiatry and political theory: the psychiatrists now wary of retrospective diagnosis in the absence of its subject, the political scientists taking individuals as identical and interchangeable pieces in a social model which excludes biological variation.

The theoretical pitfalls in the area are great, and the mistakes bizarre. In a well publicised report, a group of American psychiatrists argued that Senator
Barry Goldwater, then a candidate for the Presidency, was mentally unstable and were very nearly sued (Ballard, 1973). Similarly, the Press Council ruled that the Sun newspaper improperly published 'a psychiatrist's' opinion on the mental health of the Labour politician Tony Benn. On the whole, perhaps because psychopathology is a measure of 'difference', it is the innovators who tend to be perceived as insane, while the conservatives form the undifferentiated building blocks of the social theorist; Goldwater is (arguably) an exception.

Beyond the dangers of facile denigration and the political use of psychiatric categories, it does appear that one of the reasons for our refusal to venture very seriously into this area is the incommensurability of biological and social paradigms, the one articulating causal-linear models which presume events independent of our apperception of them, the other incorporating such characteristically human attributes as volition, identity, and memory.

It seems to me that one way of proceeding here is to avoid simplistic overall models of the interrelationship of biological difference with social difference, and to examine in certain limited cases how our two paradigms impinge on each other in a single instance. We can either start from biology-what social facts does thyrotoxicosis embody and represent? - or from sociology - what psychobiological characteristics seem to 'fit' a given institution? A useful idea may be Max Weber's notion of charisma. Originally used to characterise "the social recognition of certain extrasocially sanctioned qualities imputed to the person of the leader" (Weber, 1958), charisma has become a rather degraded notion, taking on, in the hands of psychohistorians and sociologists of religion, simply an assumption of perceived 'personality', the other members of the social group becoming merely passive and credulous vehicles (following Le Bon's or Freud's notions of 'the Crowd').

To tease out the biological-social dialectic, we have to look at the social reflections of the biological data (what are local notions of idiosyncrasy, madness or personality?) to get at the intervening (psychological) processes by which individuals dynamically form or reform social groups both through identification with those aspects of the sick innovator they shared but also through a structural opposition to those which they do not (Littlewood, 1991).

The notion of the innovator simply as a charismatic madman does not get us very far in examining how new political arrangements develop at certain times, while paradoxically it leaves the leader simply as one who shares and anticipates the personal dilemmas of his/her contemporaries and, solving 